\title{
Genetics and biochemical variability of variants of 21 hydroxylase deficiency
}

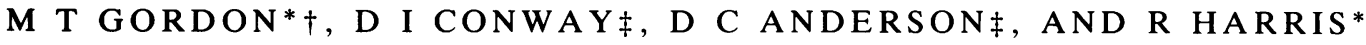

From * the Department of Medical Genetics, St Mary's Hospital, Hathersage Road, Manchester M13 0JH; and $\ddagger$ the Department of Medicine, Hope Hospital, Eccles Old Road, Salford M6 8HD.

SUMmARY In a population and family study we have examined the relationship between HLA types, classical congenital adrenal hyperplasia $(\mathrm{CAH})$, and variants of 21 hydroxylase $(21 \mathrm{OH})$ deficiency detected by increased blood levels of 17 hydroxyprogesterone (17 PO) in response to ACTH after overnight suppression with dexamethasone ('short Synacthen test'). In a non-CAH population, $7 \cdot 7 \%$ of subjects were found to have raised $17 \mathrm{PO}$ response suggesting reduced activity of $21 \mathrm{OH}$. Such subjects with raised $17 \mathrm{PO}$ levels were designated simply as type 2 responders because the relationship with genotype was unknown. Post-ACTH levels of 17 PO were significantly greater in type 2 responders than in obligate carriers of CAH. A total of $2 \cdot 5 \%$ of the population studied also had raised progesterone (PO) levels in the Synacthen test. HLA-A28 and B14 (in linkage disequilibrium) were significantly increased in frequency and HLA-B12 decreased in the type 2 responders. HLA-Bw47, which is known to be associated with $\mathrm{CAH}$, was found only among obligate carriers of classical $\mathrm{CAH}$. Because type 2 response and classical CAH are linked to HLA but are associated with different antigens, it is likely that they are determined by two (or more) alleles.

Congenital adrenal hyperplasia $(\mathrm{CAH})$ resulting in infantile virilisation with or without salt loss, due to 21 hydroxylase $(21 \mathrm{OH})$ deficiency, is inherited as an autosomal recessive linked to the HLA system. ${ }^{1}$ Recent reports describe two variants of $21 \mathrm{OH}$ deficiency, not evident at birth, which have been designated respectively as 'cryptic' and 'late onset'. ${ }^{3}$ Persons with the cryptic form have no relevant symptoms while women with late onset 21 $\mathrm{OH}$ deficiency present with amenorrhoea and virilisation. In both instances the severity of the biochemical abnormality, as reflected in peaks of 17 hydroxyprogesterone (17 PO) after ACTH, was only marginally less than that found in classical (homozygous) $\mathrm{CAH}^{4}{ }^{4}$ These variants do occasionally occur in families where the proband has classical CAH. ${ }^{56}$ However, it is now well established that both cryptic and late onset forms of 21 hydroxylase deficiency are associated with a preponderance of HLA-B14, ${ }^{7}$ and classical CAH with a different antigen, HLA-Bw47. ${ }^{8}$

†Present address: Department of Chemical Pathology, Clinical Sciences Building, Hope Hospital, Eccles Old Road, Salford M6 8HD.

Received for publication 30 May 1984.

Accepted for publication 23 November 1984.
We have reported population studies ${ }^{9}{ }^{10}$ in which apparently normal subjects with no known family history of CAH had raised levels of $17 \mathrm{PO}$ in response to ACTH stimulation. These were designated simply as type 2 responders because the relationship to the various forms of $21 \mathrm{OH}$ deficiency was unknown. In some instances there was a concomitant excessive rise in progesterone (PO) levels and the response of $17 \mathrm{PO}$ to ACTH was frequently greater than that seen in obligate carriers of CAH. Early in these studies we encountered some women with type 2 response who were infertile. This led us to undertake a study of the frequency of this variant which we then showed was not related to any specific form of female infertility. ${ }^{10}$

We were able to take advantage of this extensive clinical study to examine the genetics of type 2 response and to relate this to classical $\mathrm{CAH}$ by investigating the HLA types and $17 \mathrm{PO}$ and $\mathrm{PO}$ responses to ACTH in normal volunteers, gynaecology clinic patients, the families of type 2 responders, and obligate carriers of classical CAH. We examine here the relationship of type 2 responses to cryptic, late onset, and classical $\mathrm{CAH}$ and the 
possibility that the type 2 response represents another allelic variant of 21 hydroxylase.

\section{Subjects and methods}

A total of 341 subjects was investigated after the studies had been approved by the Salford Area Ethical Committee and fully informed consent had been obtained. The patient groups were as follows.

(1) Eighty-nine volunteers (65 females, 24 males), mainly hospital medical and laboratory staff.

(2) Two hundred and four female endocrine clinic patients referred with a variety of problems described in detail previously. ${ }^{9}$

(3) Eleven (six male, five female) parents of children with classical congenital adrenal hyperplasia $(\mathrm{CAH})$ due to $21 \mathrm{OH}$ deficiency.

(4) Thirty-seven members of eight families ascertained through a proband with type 2 response from groups (1) and (2) above.

In subject groups 1 and 2, 60 minute $17 \mathrm{PO}$ levels were estimated in 285 subjects, 60 minute PO levels in 279, and both steroids in 274 .

HLA, Bf, and glyoxalase I (GLO) typing was performed on the following.

(i) Thirteen type 2 responders detected following investigation of groups (1) and (2) above.

(ii) Seventy-six unrelated persons with normal 17 PO levels from groups (1) and (2) above. These were all randomly selected.

(iii) Seventy-four parents (obligate carriers) of patients with $\mathrm{CAH}$, derived from 39 families.

\section{SHORT SYNACTHEN ADRENAL STIMULATION TEST}

Dexamethasone $(1.5 \mathrm{mg})$ was administered orally at 23.00 hours. After an overnight fast, Synacthen (1-24 ACTH, $250 \mu \mathrm{g}$ ) was given intramuscularly between 09.00 and 10.00 hours. Blood was taken at 0 and 60 minutes, allowed to clot, centrifuged, and the serum stored at $-20^{\circ} \mathrm{C}$ until the time of assay. All female subjects were tested within seven days of the onset of menstruation, at a time when ovarian secretion of PO and $17 \mathrm{PO}$ were at a minimum.

STEROID ASSAYS

$17 \mathrm{PO}$ and $\mathrm{PO}$ were measured by radioimmunoassay after ether extraction and celite column fractionation. ${ }^{11}$

HLA TYPING

HLA-A and -B typing was performed by the standard NIH two stage microlymphocytotoxicity test. One hundred and twelve well defined sera were used to identify most of the antigens. A monospecific antiserum was available for HLA-Bw47 which was also detected by a pattern of extra reactions in three antisera for HLA-B40 cross reacting groups. Glyoxalase I phenotyping was performed on red cell lysates using a modification of the method of Kompf et $a l^{12}$ and $\mathrm{Bf}$ typing by immunofixation after electrophoretic separation of sera in agarose gels. ${ }^{13}$

STATISTICAL ANALYSIS

The steroid data were analysed using the statistical package for the social services on the 7600 computer at the University of Manchester Regional Computer Centre. Increments of steroid levels during Synacthen stimulation after overnight dexamethasone suppression were calculated and groups were compared using the Mann-Whitney non-parametric tests. A graphical method making use of probability curves $^{14}$ allowed the detection of subgroups with raised $17 \mathrm{PO}$ or PO levels. Owing to difficulties in obtaining parental steroid data and HLA types, linkage was sought between HLA and type 2 response genes by the sib-pair method of Penrose. ${ }^{15}$ (It must be noted that this method overestimates significance since the standard error of the statistic is only very approximate and is an underestimate.) Delta values as a measure of linkage disequilibrium were calculated as described by Lamm and Degos. ${ }^{16}$

\section{Results}

SHORT SYNACTHEN STIMULATED STEROID

LEVELS IN THE NON-CAH POPULATION

The frequency distributions for Synacthen stimulated 17 PO and PO 60 minute incremental levels are shown in figs 1 and 2, with steroid values for each group of subjects in table 1 . A wide variation in steroid response to ACTH stimulation was observed. Some persons exhibited high levels of 17 $\mathrm{PO}$ in response to $\mathrm{ACTH}$, in some cases with a concomitant rise in $\mathrm{PO}$ which was suggestive of a reduction in adrenal 21 hydroxylase activity in these subjects. Since there was no significant difference between the normal volunteer and gynaecology patient groups for the 60 minute increment levels, data from these groups were pooled. The limits which define apparently normal $21 \mathrm{OH}$ activity were determined by plotting the 60 minute increment levels for each steroid on probability paper (figs 1 and 2). This revealed a polymodal distribution for both steroids suggesting the existence of different populations with differing $21 \mathrm{OH}$ activities. The normal limits were taken at the first point of inflexion (- - ), these being $7.0 \mathrm{nmol} / 1$ for $17 \mathrm{PO}$ and $5.0 \mathrm{nmol} / \mathrm{l}$ for PO. For $17 \mathrm{PO}, 22$ of 285 subjects tested $(7 \cdot 7 \%)$ had increment values above $7 \cdot 0$ 
TABLE 1 Steroid 60 minute increment levels following ACTH stimulation in normal male and female volunteers and in females with various gynaecological conditions.

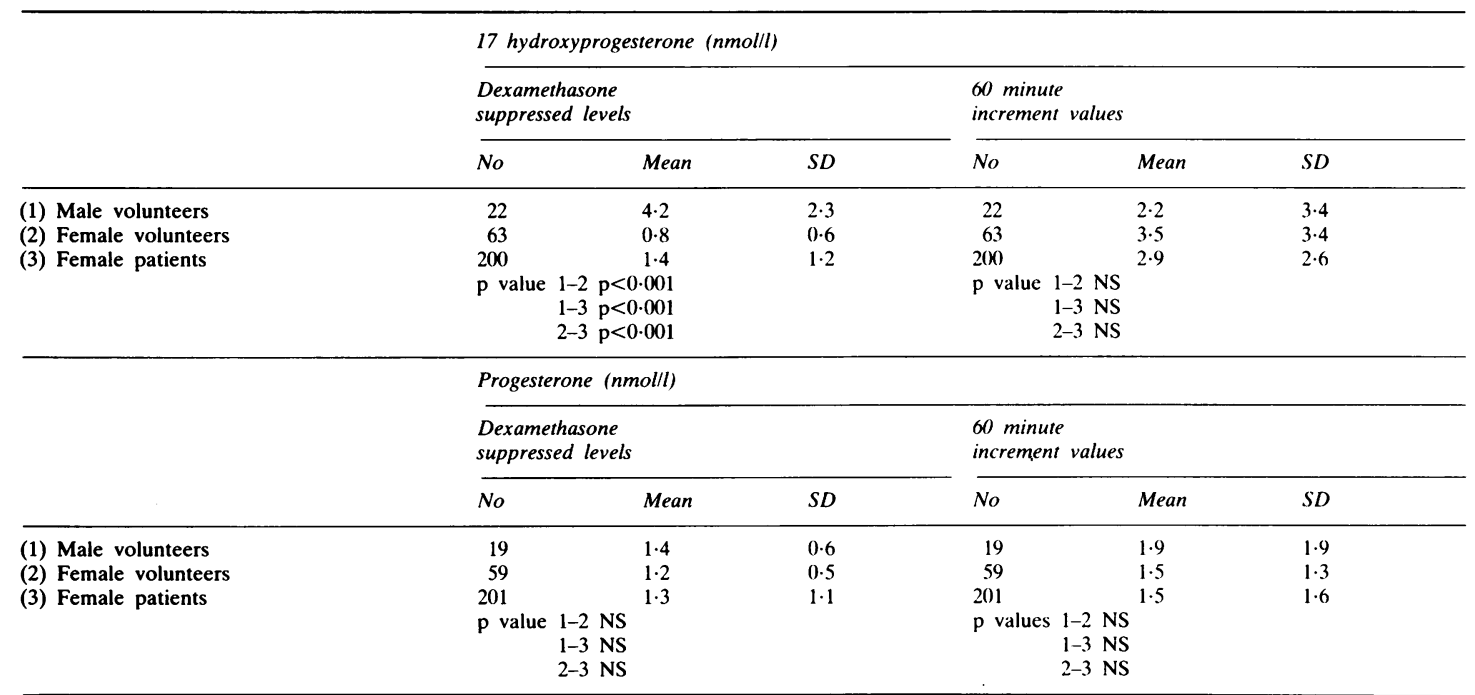

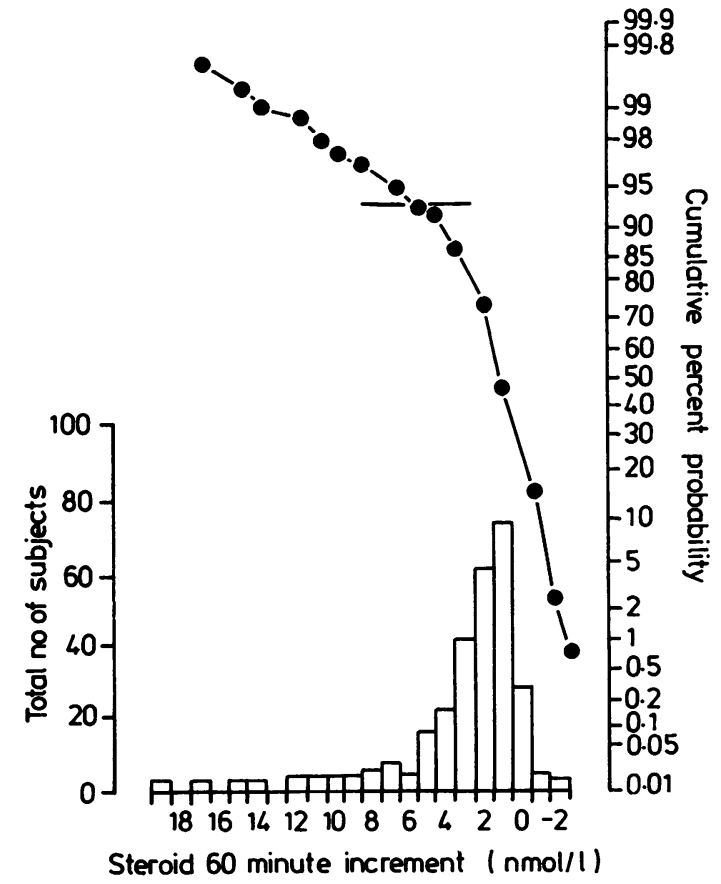

FIG $1 \overline{17} \ddot{O}$ H progesterone 60 minute increment from 285 subjects showing frequency distribution (histogram of left scale) and its transformation into cumulative percent probability (1 and right scale). represents the first point of inflexion, the limit of normal response to $A C T H$. nmol/l (from now on designated the type 2 response). These included two male volunteers, five female volunteers, and 15 gynaecological patients, representing $9 \cdot 1 \%, 9 \cdot 7 \%$, and $9 \cdot 5 \%$, respectively of each group tested. A total of $2.5 \%$ of subjects tested for PO (two male volunteers, two female volunteers, three female patients) were found to have raised increment values of this steroid.

Table 2 shows the steroid data for 274 subjects tested for both steroids and according to $17 \mathrm{PO}$ response placed into the categories of type 1 (normal response) and type 2 (raised response). For comparison, data for carriers of $\mathrm{CAH}$ are also shown.

COMPARISON OF CARRIERS OF CAH WITH TYPE I AND TYPE 2 RESPONDERS

Although CAH carriers had significantly greater 17 PO increment levels at 60 minutes than subjects with type 1 response to Synacthen $(p<0.001)$, only $45.5 \%$ of CAH carriers (four males and one female) in fact had $17 \mathrm{PO}$ levels greater than $7 \mathrm{nmol} / \mathrm{l}$. Only one female carrier was found to have a PO 6 increment value above the normal range $(5.0$ $\mathrm{nmol} / \mathrm{l})$, although there was a significant difference between carriers and type 1 responders for this steroid also $(\mathrm{p}<0 \cdot 001)$. Although the $17 \mathrm{PO}$ levels of type 2 responders were significantly greater than those of CAH carriers $(p<0.005)$, using this steroid as a marker, there was substantial overlap between 


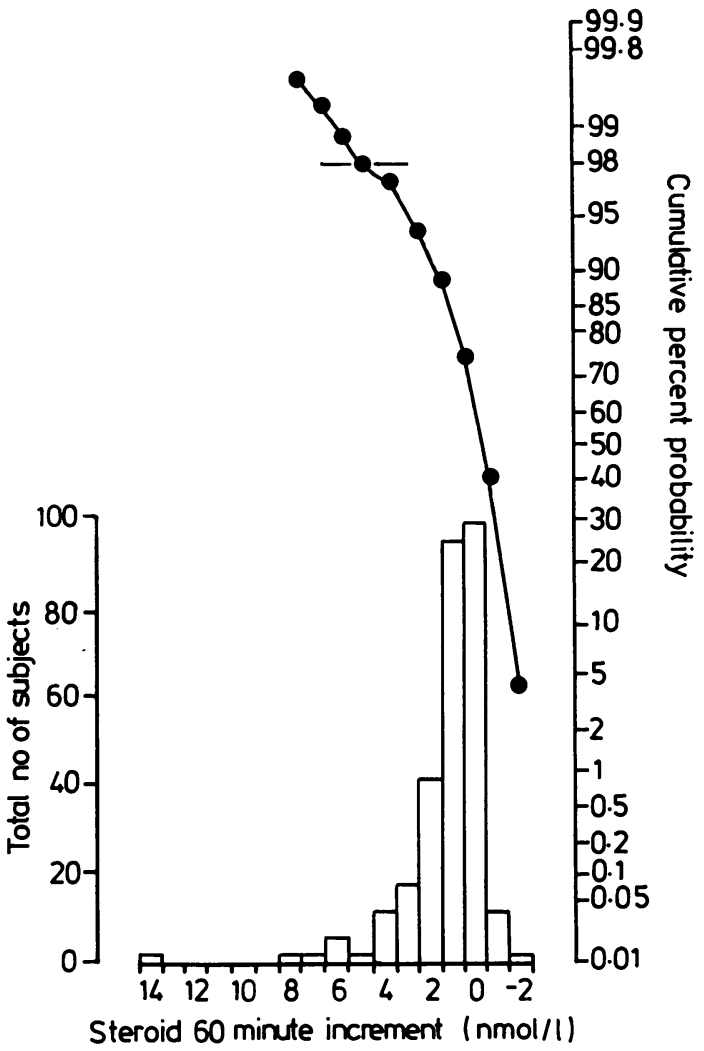

FIG 2 Progesterone 60 minute increment period data from 279 subjects showing frequency distribution (histogram of left scale) and its transformation into cumulative percent probability ( 1 and right scale). represents first point of inflexion, the limit of normal response to ACTH.

these two groups. There was no significant difference in PO increment values between type 2 responders and carriers $(p=>0.05)$.
HLA ANTIGEN FREQUENCIES

The frequencies of HLA-A and -B antigens, and of $\mathrm{Bf}$ and GLO variants in 13 unrelated type 2 responders, 76 type 1 responders, and $74 \mathrm{CAH}$ carriers are shown in tables 3 and 4. HLA-A28 and HLA-B14 were found to be increased and HLA-B12 absent among type 2 responders. These differences were significant before correction. HLA-Bw47 occurred in eight of the known carriers but in none of the type 2 responders. This association was not statistically significant. There was a significant increase in the BfF1 allele in the type 2 responder group $(p=0.0309)$ when they were compared with carriers for $\mathrm{CAH}$. The BfF1 allele was found in one A28 B14 positive subject. A delta value of $0 \cdot 118$ was calculated as a measure of linkage disequilibrium between HLA-A28 and HLA-B14 antigens among type 2 responders. This value was significant (Fisher's $p=0.0319$ ) and suggests the existence of a susceptibility haplotype.

\section{FAMILY STUDIES}

HLA genotypes of members of the families of eight index cases of type 2 response are shown in fig 3 . Nine family members were found to have raised 17 PO levels (type 2 response). These included four sibs (AII.3, DII.1, EII.1, FII.2), a half sister (EII.4), two parents (BI.1, DI.2), an uncle (EI.1), and the son of the proband in family A (AIII.1). The four sibs with type 2 response were HLA identical to the affected proband in the respective families (A, D, E, and F) while all sibs sharing only one or no haplotypes with the proband were found to have normal $17 \mathrm{PO}$ and PO increment values. Analysis of linkage between HLA and the type 2 response, by the Penrose sib pair method, ${ }^{15}$ gave a probability in favour of linkage of $p=0.003$.

\section{Discussion}

We used the short Synacthen test, after overnight dexamethasone suppression, to provide an in vivo

TABLE 260 minute stimulated levels following Synacthen stimulation in type 1 (normal) and type 2 responders and in carriers of $C A H$.

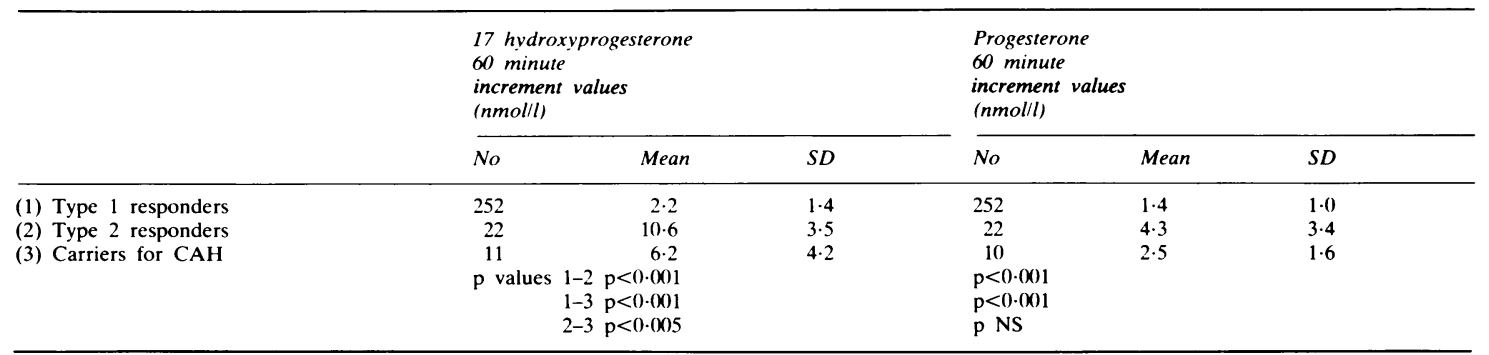

\section{The Hoagland Medical Library}


TABLE 3 Number of mutually unrelated subjects who carried specific HLA antigens among three hydroxylase phenotype classes.

\begin{tabular}{|c|c|c|c|c|c|c|c|c|c|}
\hline \multirow[t]{3}{*}{$H L A$} & & \multirow{2}{*}{\multicolumn{2}{|c|}{$\begin{array}{l}1 \\
\text { Type } 2 \\
\text { responders } \\
(n=13)\end{array}$}} & \multirow{2}{*}{\multicolumn{2}{|c|}{$\begin{array}{l}2 \\
\text { Type } 1 \\
\text { responders } \\
(n=76)\end{array}$}} & \multirow{2}{*}{\multicolumn{2}{|c|}{$\begin{array}{l}3 \\
\text { Carriers } \\
(n=74)\end{array}$}} & \multicolumn{2}{|c|}{ Significance } \\
\hline & & & & & & & & \multirow[t]{2}{*}{1 and $2^{*}$} & \multirow[t]{2}{*}{1 and $3^{*}$} \\
\hline & & No & $\%$ & No & $\%$ & No & $\%$ & & \\
\hline \multirow[t]{7}{*}{ A } & 1 & 4 & $30 \cdot 8$ & 25 & 32.9 & 20 & $27 \cdot 0$ & NS & NS \\
\hline & 2 & 4 & $30 \cdot 8$ & 37 & $48 \cdot 7$ & 39 & $52 \cdot 7$ & NS & NS \\
\hline & 9 & 4 & $30 \cdot 8$ & 12 & $15 \cdot 8$ & 9 & $12 \cdot 2$ & NS & NS \\
\hline & 10 & - & - & 10 & $13 \cdot 2$ & 8 & $10 \cdot 8$ & NS & NS \\
\hline & 11 & 3 & $23 \cdot 1$ & 4 & $5 \cdot 3$ & 11 & $14 \cdot 5$ & NS & NS \\
\hline & 19 & 1 & $7 \cdot 7$ & 18 & $23 \cdot 7$ & 14 & $18 \cdot 4$ & NS & NS \\
\hline & 28 & 5 & 38.5 & 9 & $11 \cdot 8$ & 7 & 9.5 & 0.0288 & 0.0150 \\
\hline \multirow[t]{15}{*}{ B } & 5 & 1 & $7 \cdot 7$ & 8 & $10 \cdot 5$ & 13 & $17 \cdot 6$ & NS & NS \\
\hline & 7 & 3 & $23 \cdot 1$ & 21 & $27 \cdot 6$ & 21 & $28 \cdot 4$ & NS & NS \\
\hline & 8 & 5 & $28 \cdot 5$ & 12 & $15 \cdot 8$ & 12 & $16 \cdot 2$ & NS & NS \\
\hline & 12 & - & - & 20 & $26 \cdot 3$ & 27 & $36 \cdot 5$ & 0.0275 & 0.0055 \\
\hline & 15 & - & - & 10 & $13 \cdot 2$ & 7 & $9 \cdot 4$ & NS & NS \\
\hline & 16 & 2 & $15 \cdot 4$ & 3 & 3.9 & 2 & $2 \cdot 7$ & NS & NS \\
\hline & 17 & 1 & $7 \cdot 7$ & 10 & $13 \cdot 2$ & 7 & $9 \cdot 4$ & NS & NS \\
\hline & 18 & 1 & $7 \cdot 7$ & 4 & $5 \cdot 3$ & 4 & $5 \cdot 4$ & NS & NS \\
\hline & 21 & - & - & 3 & 3.9 & 1 & $1 \cdot 3$ & NS & NS \\
\hline & 22 & 1 & $7 \cdot 7$ & 2 & $2 \cdot 6$ & 3 & $4 \cdot 1$ & NS & NS \\
\hline & 27 & - & - & 5 & 6.6 & 3 & $4 \cdot 1$ & NS & NS \\
\hline & 35 & 4 & $30 \cdot 8$ & 19 & $25 \cdot 0$ & 8 & $10 \cdot 8$ & NS & NS \\
\hline & 37 & - & - & 3 & 3.9 & 2 & $2 \cdot 7$ & NS & NS \\
\hline & 40 & - & - & 8 & $10 \cdot 5$ & 15 & $20 \cdot 3$ & NS & NS \\
\hline & 47 & - & - & 1 & $1 \cdot 3$ & 8 & $10 \cdot 8$ & NS & NS \\
\hline
\end{tabular}

NS=non-significant.

*=Fisher's exact probability (one sided), uncorrected for number of observations.

measurement of 21 hydroxylase activity, assuming that an unusually high $17 \mathrm{PO}$ response reflects a reduction in 21 hydroxylase activity. However, we and others ${ }^{17^{-}}$have found that this method does not provide very good discrimination of obligate carriers of 21 hydroxylase deficiency.

In the present investigations, $7 \cdot 7 \%$ of those tested (in whom there was no reason to suspect classical $\mathrm{CAH}$ ) were found to have evidence in the short Synacthen test suggestive of some impairment of 21 hydroxylase activity (the type 2 response). Since this is at least three times the estimated frequency of carriers for classical CAH $(2 \cdot 3 \%),{ }^{18}$ another explanation was sought for the majority of cases with a type 2 response. Only $45 \%$ of obligate carriers tested gave a positive response for Synacthen, with the implication that about $88.0 \%$ of subjects with raised $17 \mathrm{PO}$ levels were not carriers of classical $\mathrm{CAH}$.

In earlier studies, we have found classical $\mathrm{CAH}$ to

TABLE 4 Frequency of $B f$ and $G L O$ alleles in type 2 responders compared with type 1 responders and carriers for CAH.

\begin{tabular}{|c|c|c|c|c|c|c|c|c|}
\hline \multirow[t]{3}{*}{ Allele } & \multirow{2}{*}{\multicolumn{2}{|c|}{$\begin{array}{l}\text { I } \\
\text { Type } 2 \\
\text { responders }\end{array}$}} & \multirow{2}{*}{\multicolumn{2}{|c|}{$\begin{array}{l}2 \\
\text { Type } 1 \\
\text { responders }\end{array}$}} & \multirow{2}{*}{\multicolumn{2}{|c|}{$\begin{array}{l}3 \\
\text { Carriers }\end{array}$}} & \multicolumn{2}{|c|}{ Significance level } \\
\hline & & & & & & & \multirow[t]{2}{*}{1 and 2} & \multirow[t]{2}{*}{1 and 3} \\
\hline & No & $\%$ & No & $\%$ & No & $\%$ & & \\
\hline Bf $F$ & 2 & $8 \cdot 3$ & 26 & $20 \cdot 6$ & 23 & $20 \cdot 9$ & NS & NS \\
\hline S & 20 & $83 \cdot 3$ & 95 & $75 \cdot 4$ & 87 & $79 \cdot 1$ & NS & NS \\
\hline F1 & 2 & $8 \cdot 3$ & 3 & $2 \cdot 4$ & - & - & NS & 0.0309 \\
\hline \multirow[t]{2}{*}{ S1 } & - & - & 2 & 1.6 & - & - & NS & - \\
\hline & \multicolumn{2}{|c|}{$H=24$} & \multicolumn{2}{|c|}{$\mathrm{H}=126$} & \multicolumn{2}{|c|}{$H=110$} & & \\
\hline \multirow{3}{*}{$\begin{array}{rr}\text { GLO } & 2 \\
1\end{array}$} & 16 & $66 \cdot 7$ & 77 & $57 \cdot 5$ & 27 & $61 \cdot 4$ & NS & NS \\
\hline & 8 & $33 \cdot 3$ & 57 & $42 \cdot 5$ & 17 & $38 \cdot 6$ & NS & NS \\
\hline & & & \multicolumn{2}{|c|}{$\mathrm{H}=134$} & \multicolumn{2}{|c|}{$H=44$} & & \\
\hline
\end{tabular}

$\mathbf{H}=$ No of haplotypes 
Family A

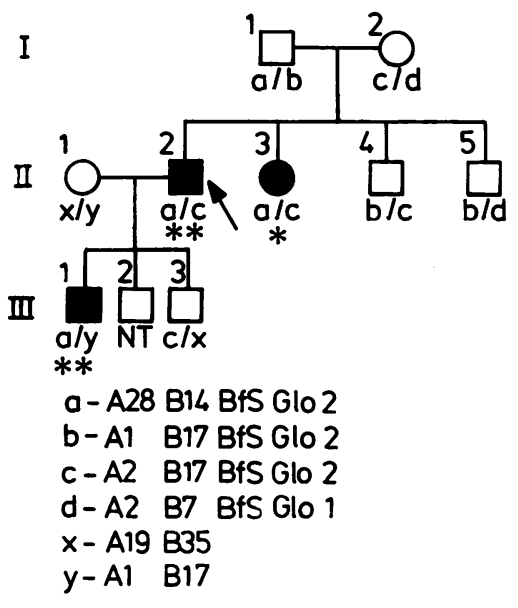

Family B

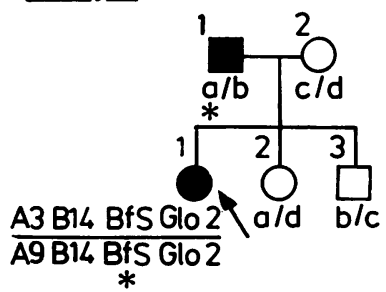

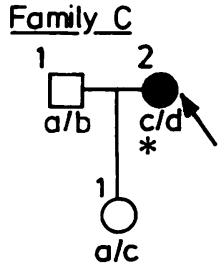

$\begin{array}{ll}a-A 32 & B 15 \\ b-A 2 & B 5 \\ c-A 3 & B 7 \\ d-A 9 & B 22\end{array}$

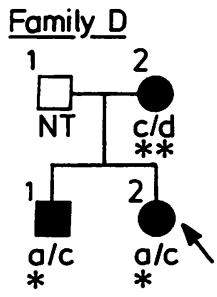

a-A1 B8

$c-A 1$ B5

d-A3 B 40

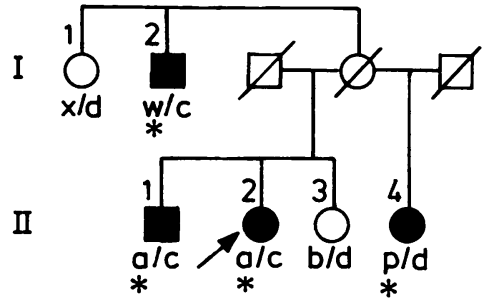
a A9 B16 BfF Glo 2
b A28B/4 BHS Glo 2
c A2 B7 BfS Glo 2
d All B22 BtS Glo 1
w An B17 BtS Glo 2
$\times$ Al B7 BfF Glo 2
P A9 B4L BfF Glo 2

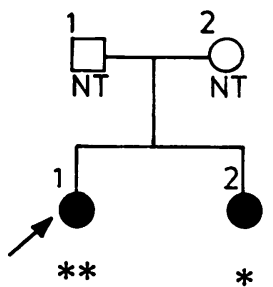

II.1 A2 A28 B14 B18 BfF, SGlo 2,1 II.2 A2 A28 B14 B18BFF, SGlo 2,1

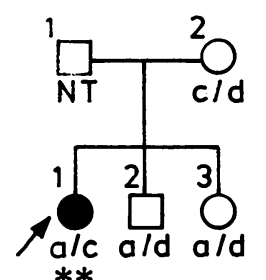

- A3 B35 Glo 2

c An B8 Glo 2

d A2 B12 Gb 2

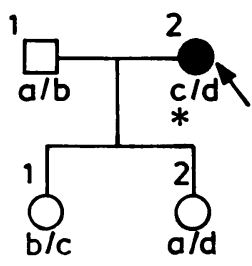

a A9 B7 Glo 1

b A2 B15 Glo 2

c A1 B8 Glo 2

d A3 Bx Glo 2

FIG 3 HLA genotypes and $17 \mathrm{OH}$ progesterone and progesterone 60 minute incremental values in eight families with type 2 responders. $17 \mathrm{OH}$ progesterone and progesterone increments 60 minutes after ACTH are qualitatively indicated as follows: ** denotes raised $17 \mathrm{OH}$ progesterone and progesterone levels; *denotes raised $17 \mathrm{OH}$ progesterone but normal progesterone increments. (- family members with type 2 response. NT=not tested for steroid levels or HLA.

be associated with HLA-Bw47. ${ }^{\searrow}$ In the present investigations, HLA-Bw47 was found only in obligate CAH carriers, while A28 and B14 (in linkage disequilibrium) were found to be significantly associated $(p=0.0319)$ with the type 2 response and not with CAH. HLA-B14 has been previously reported to be associated with cryptic and late onset $\mathrm{CAH}^{7}$ which are probably one and the same condition. However, published data suggest that in such cases the $17 \mathrm{PO}$ response is similar to that seen in classical $\mathrm{CAH}^{4}$ with an order of magnitude greater than the type 2 response that we have described. The latter response might therefore be associated with the heterozygous state but not the homozygous state for late onset/cryptic CAH.

There was evidence of familial segregation of the type 2 response with HLA. In four families, sibs had a type 2 response and were found to be HLA identical which suggested strongly that the response was a homozygous condition controlled by a gene linked to HLA and therefore probably a variant 21 hydroxylase. We believe that type 2 responses may 
TABLE 5 Possible scheme to account for clinical and biochemical variation in 21 hydroxylase activity, based on one 'normal' and three CAH allelic forms of the enzyme.

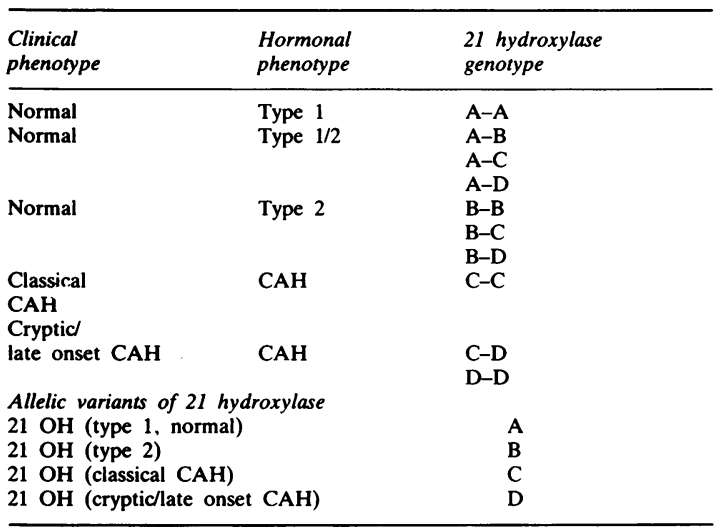

occur in both heterozygotes and homozygotes, as is suggested by the family data where some non-HLA identical relatives were found to have raised $17 \mathrm{PO}$ levels.

It has been suggested that there are at least two deficiency alleles, namely classical and late onset/ cryptic, ${ }^{5}$ at one or more genetic loci linked to HLA. We propose that the type 2 response may represent another allelic variant of 21 hydroxylase. In table 5, a scheme is presented to describe the possible biochemical and clinical permutations that could be predicted in the population if this is true.

It is clear that the short Synacthen test cannot distinguish between these possible genetic compounds. If our explanation is correct, then a biochemical test of hydroxylase activity cannot be used as a means of reliably detecting the carrier state of classical $\mathrm{CAH}$ in the general population. In families with a known case of CAH, HLA studies are likely to remain the most suitable approach for detecting carriers, to be superseded perhaps eventually by DNA restriction enzyme analysis of the major histocompatibility system.

\footnotetext{
References

1 Dupont B, Oberfield SE, Smithwick EM, Lee TD, Levine LS Close genetic linkage between HLA and congenital adrenal hyperplasia (21 hydroxylase deficiency). Lancet 1977;ii:130912.
}

${ }^{2}$ Levine LS, Dupont B, Lorenzen F, et al. Cryptic 21 hydroxylase deficiency in families of patients with classical congenital adrenal hyperplasia. J Clin Endocrinol Metab 1980;51:1316-24.

${ }^{3}$ Laron Z, Pollack MS, Zamir R, et al. Late onset 21 hydroxylase deficiency and HLA in the Ashkenazi population. Hum Immunol 1980;1:55-66.

${ }^{4}$ New MI, Lorenzen F, Lerner AJ, et al. Genotyping, steroid 21 hydroxylase deficiency hormonal reference data. J Clin Endocrinol Metab 1983;57:320-6.

5 Kohn D, Levine LS, Pollack MS, et al. Late onset steroid 21 hydroxylase deficiency. A variant of classical congenital adrenal hyperplasia. J Clin Endocrinol Metab 1982;55:817-27.

6 Levine LS, Dupont B, Lorenzen F, et al. Genetic and hormonal characterisation of cryptic 21 hydroxylase deficiency. $J$ Clin Endocrinol Metab 1981:53:1193-8.

7 Pollack MS, Levine LS, O'Neill GF, et al. HLA linkage and B14, DR1, Bfs haplotype association with the genes for late onset and cryptic 21 hydroxylase deficiency. Am J Hum Genet 1981;33:540-50.

${ }^{8}$ Klouda PT, Harris R, Price DA. Linkage and association between HLA and 21 hydroxylase deficiency. $J$ Med Genet 1980;17:337-41.

9 Child DF, Bu'Lock DE, Hillier VF, Anderson DC. Heterogeneity in adrenal steroidogenesis in normal men and women. Clin Endocrinol 1979;11:383-9.

10 Conway DI, Anderson DC, Gordon MT, Bu'Lock DE, Hillier VF. Adrenal progesterone, 17 hydroxyprogesterone, and cortisol responses to Synacthen in normal women and women with various gynaecological disorders. Clin Endocrinol 1983;19:7785 .

11 Anderson DC, Hopper BR, Lasley BR, Yen SSC. A simple method for the assay of eight steroids in small volumes of plasma. Steroids 1976;28:179-96.

12 Kompf J, Bissbart S, Gussman S, Rittner H. Polymorphism of red cell glyoxylase I: a new genetic marker in man. Investigation of 169 mother-child combinations. Humangenetik 1975;21:1413.

13 Alper CA, Boenisch T, Watson L. Genetic polymorphism in human glycine-rich beta glycoprotein. J Exp Med 1972;135:6880.

14 Harding JP. The use of probability paper for the graphical analysis of polymodal frequency distributions. J Mar Biol Assoc 1949;28:141-53.

15 Penrose LS. The detection of autosomal linkage data which consists of pairs of brothers and sisters of unspecified parentage. Ann Eugen 1935;6:133-8.

${ }^{16}$ Lamm LU, Degos L. Introduction to HLA genetics. In: Dick HM, Kissmeyer-Nelson F, eds. Histocompatibility techniques. Amsterdam: Elsevier-North Holland Biochemical Press, 1979:131-62.

17 Grosse-Wilde H, Weild J, Albert E, Scholt S, Bidlingmaier F, Sippel WG. Genetic linkage studies between congenital adrenal hyperplasia and the HLA blood group system. Immunogenetics 1979;8:41-9.

${ }^{18}$ Hubble D. Congenital adrenal hyperplasia. In: Holt KS, Ravie $\mathrm{N}$ RN, eds. Basic concepts of inborn errors and defects of steroid biosynthesis. Edinburgh: Churchill Livingstone, 1966:68-74.

Correspondence and requests for reprints to Dr M T Gordon, Department of Clinical Pathology, Clinical Sciences Building, Hope Hospital, Eccles Old Road, Salford M6 8HD. 